\title{
SOME NORM INEQUALITIES INVOLVING FUNCTIONS OF TWO VARIABLES
}

\author{
MANDEEP Singh AND JASPAL SingH AuJla
}

Abstract. We will prove some inequalities for unitarily invariant norms involving functions of two variables. Some of our results generalize known results.

Mathematics subject classification (1991): 47A63.

Key words and phrases: Norm inequalities, matrix functions, operator monotone functions.

\section{REFERENCES}

[1] T. ANDo, Operator-Theoretic Methods for Matrix Inequalities, Survey article, 1998.

[2] T. ANO AND K. OKUBO, Induced norms of the Schur multiplier operator, Linear Alg. Appl. 147 (1991), 181-199.

[3] J. S. Aujla And H. L. Vasudeva, Convex and monotone operator functions, Ann. Polon. Math 62 (1995), 1-11.

[4] R. Bhatia, Matrix Analysis, Springer Verlag, 1997.

[5] R. Bhatia AND C. DAVIS, More matrix forms of the arithmetic-geometric mean inequality, Siam J. Matrix Analysis Appl. 14 (1993), 132-136.

[6] R. BHATIA AND F. KITTANEH, On the singular values of a product of operators, Siam J. Matrix Analysis Appl. 11 (1990), 272-277.

[7] R. Bhatia And K. R. Parthasarthy, Positive definite functions and operator inequalities, (preprint), 1998.

[8] F. KitTANEH, A note on the arithmetic-geometric mean inequality for matrices, Linear Alg. Appl 171 (1992), 1-8.

[9] A. KORANYI, On some classes of analytic functions of several variables, Trans. Amer. Math. Soc. 101 (1961), 521-524.

[10] R. MATHIAS, An arithmetic-geometric mean inequality involving Hadamard products, Linear Alg. Appl. 184 (1993), 71-78.

[11] A. W. Roberts and D. E. Varbag, Convex functions, Academic Press, New York and London, 1973. 